\title{
SVN \\ Current management of spontaneous intracerebral haemorrhage
}

\author{
Cyrus K Dastur, Wengui Yu
}

To cite: Dastur CK, Yu W. Current management of spontaneous intracerebral haemorrhage. Stroke and Vascular Neurology 2017;2: e000047. doi:10.1136/svn2016-000047

Received 10 October 2016 Accepted 8 November 2016 Published Online First 24 January 2017

Department of Neurology, University of California Irvine, Irvine, California, USA

Correspondence to Dr Wengui Yu; wyu@uci.edu

\section{ABSTRACT}

Intracerebral haemorrhage (ICH) is the most devastating and disabling type of stroke. Uncontrolled hypertension (HTN) is the most common cause of spontaneous ICH. Recent advances in neuroimaging, organised stroke care, dedicated Neuro-ICUs, medical and surgical management have improved the management of ICH. Early airway protection, control of malignant HTN, urgent reversal of coagulopathy and surgical intervention may increase the chance of survival for patients with severe $\mathrm{ICH}$. Intensive lowering of systolic blood pressure to $<140 \mathrm{~mm} \mathrm{Hg}$ is proven safe by two recent randomised trials. Transfusion of platelets in patients on antiplatelet therapy is not indicated unless the patient is scheduled for surgical evacuation of haematoma. In patients with small haematoma without significant mass effect, there is no indication for routine use of mannitol or hypertonic saline (HTS). However, for patients with large ICH (volume $>30$ cbic centmetre) or symptomatic perihaematoma oedema, it may be beneficial to keep serum sodium level at $140-150 \mathrm{mEq} / \mathrm{L}$ for $7-10$ days to minimise oedema expansion and mass effect. Mannitol and HTS can be used emergently for worsening cerebral oedema, elevated intracranial pressure (ICP) or pending herniation. HTS should be administered via central line as continuous infusion $(3 \%)$ or bolus $(23.4 \%)$. Ventriculostomy is indicated for patients with severe intraventricular haemorrhage, hydrocephalus or elevated ICP. Patients with large cerebellar or temporal ICH may benefit from emergent haematoma evacuation. It is important to start intermittent pneumatic compression devices at the time of admission and subcutaneous unfractionated heparin in stable patients within 48 hours of admission for prophylaxis of venous thromboembolism. There is no benefit for seizure prophylaxis or aggressive management of fever or hyperglycaemia. Early aggressive comprehensive care may improve survival and functional recovery.

\section{INTRODUCTION}

Intracerebral haemorrhage (ICH) affects $>1$ million people annually worldwide and is the deadliest and most disabling type of stroke. ${ }^{12}$ Uncontrolled hypertension (HTN) is the most common risk factor for spontaneous ICH. ${ }^{3}{ }^{4}$ The incidence of ICH is higher in Asians, partly due to limited primary care for HTN and non-compliance. ${ }^{5}$ Primary prevention with antihypertensive medication is likely the most effective strategy to reduce the burden of ICH. Although only accounting for $\sim 10-15 \%$ of all stroke in the USA, ICH causes a disproportionately high level of morbidity and mortality. ${ }^{7}$ In 2010 alone, 62.8 million disability-associated life-years (DALY) were lost compared with 39.4 million DALYs lost due to ischaemic stroke. Despite age-standardised mortality rates from ICH decreasing by over $25 \%$ over the last 15 years, 3.2 million deaths were attributed to ICH vs 3.3 million deaths from ischaemic stroke in 2013 alone. $^{7}$

Population-based studies suggest that the majority of patients with small ICH are readily survivable with good medical care. ${ }^{8}$ For patients with large ICH, comprehensive multidisciplinary care is essential to minimise morbidity and mortality. Multiple studies have shown that caring for patients with ICH in dedicated neurological intensive care units by a specialised neurocritical care team results in significantly reduced length of stay and mortality. ${ }^{9-11}$ In recent years, numerous clinical trials have examined various medical and surgical options for ICH. This review will summarise the advances in the evaluation and management of ICH.

\section{CLASSIFICATION}

Spontaneous ICH is defined as intraparenchymal bleeding in the absence of trauma or surgery. Common risk factors for spontaneous ICH include HTN, age, history of heavy alcohol, methamphetamine or cocaine use, education at less than a high school level and genetic alleles associated with cerebral amyloid. $^{3}{ }^{4} 12-14$

Spontaneous ICH can be classified as either primary or secondary depending on the underlying cause. Primary ICH accounts for $\sim 70-80 \%$ of cases and is due to spontaneous rupture of small vessels damaged by HTN or amyloid angiopathy. Primary ICH is also classified by location as lobar versus non-lobar and supratentorial versus infratentorial. ${ }^{15}$ 


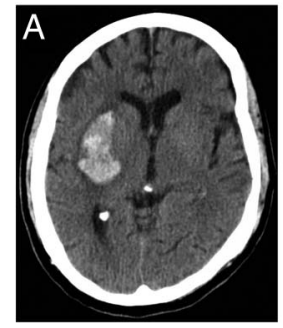

Putamen

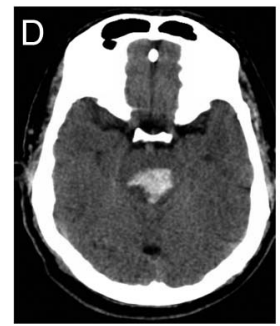

Pons

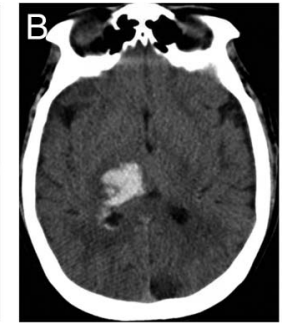

Thalamus

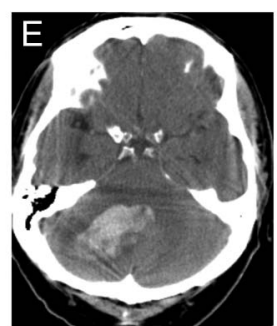

Cerebellum

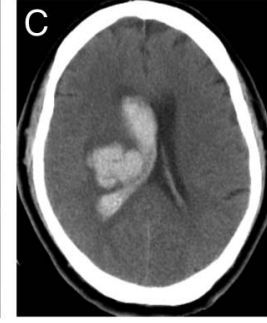

Subcortical

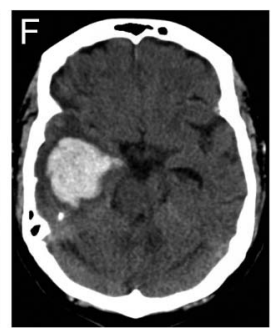

Temporal lobe
Figure 1 Typical locations of hypertensive $\mathrm{ICH}$ are putamen $(A)$, thalamus (B), subcortical white matter (C), pons (D) and cerebellum $(E)$. Thalamic and subcortical haemorrhages often extend into ventricles (B and $\mathrm{C}$ ). $\mathrm{CAA}$, drug abuse or vascular anomaly often causes lobar haemorrhage $(F) . \mathrm{ICH}$,

intracerebral haemorrhage; CAA, cerebral amyloid angiopathy.

Lobar ICH is commonly the result of cerebral amyloid angiopathy (CAA). ${ }^{14}$ Amyloid deposition in small-sized to medium-sized cortical perforators may lead to the rupture of these vessels, resulting in asymptomatic microhaemorrhages or symptomatic lobar haemorrhages. ${ }^{14}$ Non-lobar ICH is most often the result of long-standing high blood pressure resulting in lipohyalinosis of small perforating arteries of the basal ganglia, thalamus, pons and cerebellum, leading to deep haemorrhages, often with extension into the ventricles. ${ }^{12} 15$ The most common locations of hypertensive ICH are the putamen, thalamus, subcortical white matter, pons and cerebellum (figure 1).

Secondary ICH is associated with a number of congenital and acquired conditions such as vascular malformations, tumours, coagulation disorders, use of anticoagulants and thrombolytic agents, cerebral vasculitis, drug abuse and cerebral venous thrombosis. ${ }^{3} 1617$

\section{EARLY DIAGNOSIS}

ICH should be suspected in any patient with severe headache, vomiting, elevated systolic blood pressures or decreased level of consciousness. ${ }^{16}$ Rapid diagnosis is crucial for appropriate care and better functional outcomes. Early deterioration in the first few hours after initial onset is common, from haematoma expansion and from secondary injury. ${ }^{18-20}$ In addition to a prompt clinical history and neurological examination, rapid neuroimaging with a non-contrast head CT is highly sensitive and specific for ICH and is the key to early diagnosis. $^{21} 22$ CT scan will reveal not only the location and size of the ICH but also intraventricular extension, mass effect, hydrocephalus and early signs of herniation.

Haematoma volume can be estimated on head CT using the $\mathrm{ABC} / 2$ method, where $\mathrm{A}$ is maximal haematoma diameter on the axial slice with largest haematoma area, B is maximal haematoma diameter perpendicular to $\mathrm{A}$ and $\mathrm{C}$ is the number of CT slices with haematoma multiplied by slice thickness (ignoring slices with $<25 \%$ of haematoma area compared with the reference slice). ${ }^{21}{ }^{22}$ This method of haematoma volume calculation, while variable between examiners, has been shown to be effective for clinical decision-making. ${ }^{17} 22$

MRI can be as sensitive as CT in determining the presence of haemorrhage, but rarely offers additional information in the acute setting. The time and transportation required for MRI can be detrimental due to a high risk of deterioration during the first few hours. Delayed MRI is better utilised as an adjunct tool to aid in determination of the underlying cause of the ICH (such as CAA, cavernoma and tumour). ${ }^{16}$

CT angiogram is very sensitive for identifying associated vascular abnormalities and contrast extravasation as 'spot sign'. ${ }^{23}$ Contrast extravasation during angiography is associated with ongoing bleeding and increased mortality. The risk of contrast extravasation is increased with extreme HTN, depressed consciousness and large haemorrhages. A newer technique for determining haematoma expansion, the 'leakage sign', has higher sensitivity and specificity for haematoma expansion than the spot sign, and showed a significant association with poor outcomes. ${ }^{24}$ However, the requirement for an additional CT scan and greater radiation exposure may limit its clinical utility.

Repeat imaging study should be considered for evaluation of any acute deterioration in the neurological examination or for follow-up of any underlying lesion or vascular anomaly.

\section{EMERGENT INTERVENTION}

ICH is a medical emergency requiring urgent therapy given that $>20 \%$ of patients experience a decrease of 2 or more points in their Glasgow Coma Scale (GCS) after their initial assessment by Emergency Medical Services (EMS). ${ }^{25}$ In addition, $15-23 \%$ of patients have haematoma expansion and neurological decline in the first several hours. ${ }^{25} 26$

Stabilisation of airway, breathing and circulation (ABCs) is essential for preventing secondary injury from hypoxaemia, HTN and haematoma expansion. Intubation for airway protection is indicated in patient with GCS $\leq 8$ or significant respiratory distress. Patient with a decreased level of consciousness from intraventricular haemorrhage with hydrocephalus, mass effect or brainstem herniation should receive ventriculostomy, hyperosmolar therapy with mannitol $0.5-1 \mathrm{~g} / \mathrm{kg}$ or hypertonic saline (HTS) infusion. The Emergency Department (ED) algorithm for early diagnosis and emergent intervention is shown in figure 2. 
Suspected ICH

Brain Attack Activation

Single alpha page: stroke team , CT technician, and Neuro ICU charge nurse

Initial Evaluation

- Check and secure Airway, Breathing, and Circulation

- Peripheral IV placement and blood draw for coag, CBC, and CMP

- Supplemental $\mathrm{O}_{2}$ to keep $\mathrm{O}_{2}$ sat $>92 \%$

- Continued pulse oximetry and cardiac monitor

- Physical and neurological exam

- Non-contrast head CT: target door to CT time $\leq 20$ minutes of ED arrival

CT evidence of ICH

- Labetalol $10 \mathrm{mg}$ and/or hydralazine $10 \mathrm{mg}$ iv prn to keep SBP to $\leq 140 \mathrm{mmHg}$

- Start Nicardipine infusion $5-15 \mathrm{mg} / \mathrm{hr}$ as needed

- Emergent reversal of coagulopathy (see Fig. 3).

- Mannitol 0.5-1 gm iv bolus or hypertonic saline for mass effect or herniation

Surgical Indications?

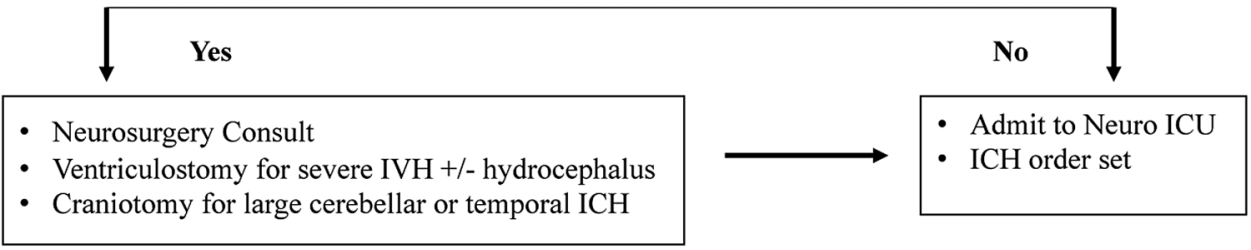

Figure 2 The ED algorithm for early diagnosis and emergent intervention. ICH, intracerebral haemorrhage.

\section{Management of HTN}

Patients with ICH very often present with significantly elevated blood pressure. Elevated systolic blood pressure (SBP) is associated with haematoma expansion, neurological deterioration and poor outcomes after ICH. ${ }^{27-29}$

In the past, there was concern about perihaematomal ischaemia from aggressive early blood pressure reduction. Recent studies showed no evidence of ischaemia in the perihaematoma zone. ${ }^{28} 29$ Two large phase III, multicentre, prospective randomised controlled trials have showed that early lowering of SBP to $<140 \mathrm{~mm} \mathrm{Hg}$ is safe without significant adversary effects. ${ }^{30}{ }_{31}$ The INTERACT-2 trial comparing early lowering of SBP to $<140 \mathrm{~mm} \mathrm{Hg}$ with $<180 \mathrm{~mm} \mathrm{Hg}$ showed no increase in adverse events in the aggressive treatment group. ${ }^{30}$ There was no significant difference in death or severe disability at 90 days. An ordinal analysis of modified Rankin scores indicated improved functional outcomes with intensive lowering of blood pressure. The Antihypertensive Treatment of Acute Cerebral Hemorrhage (ATACH) II trial used intravenous nicardipine within 3 hours of ICH onset to target SBP $\leq 140 \mathrm{~mm} \mathrm{Hg}$ versus SBP $\leq 180 \mathrm{~mm} \mathrm{Hg}{ }^{31}$ Participant enrolment was suspended at 1000 patients in September 2015. There was no significant difference in the primary end points of death or disability at 90 days. The study, however, showed a higher incidence of adverse renal events $(9.0 \%$ vs $4.0 \%, \mathrm{p}=0.002)$ in the intensive treatment than the standard treatment group. ${ }^{31}$ Of note, the mean minimum SBPs of the two groups during the first 2 hours were $128.9 \pm 16$ and $141.1 \pm 14.8 \mathrm{~mm} \mathrm{Hg}$, respectively, which were much lower than 150 and $164 \mathrm{~mm} \mathrm{Hg}$ achieved in the INTERACT-2 trial. The much lower minimum SBPs in the intensive treatment group in the ATACH II trial might explain the higher incidence of adverse renal events. ${ }^{31}$

Given the findings from INTERACT-2 trial, the 2015 update to the AHA/ASA Guidelines for the Management of Spontaneous ICH recommend that for patients presenting with SBP between 150 and 200, acute lowering of SBP to $140 \mathrm{~mm} \mathrm{Hg}$ is safe and may be effective for improving functional outcome. ${ }^{20}$ The optimum target for patients presenting with SBP $>220 \mathrm{~mm} \mathrm{Hg}$ is less clear, though aggressive blood pressure reduction with continuous antihypertensive drug intravenous infusion and frequent monitoring is reasonable. Any clinical deterioration in association with aggressive reduction of blood pressure should lead to a reassessment of the target blood pressure. ${ }^{20}$

Intravenous calcium channel blockers (eg, nicardipine) and $\beta$-blockers (eg, labetalol) are the treatment of choice for early BP reduction, given their short half-life and ease of titration. ${ }^{32}$ Nitrates should be avoided given potential for cerebral vasodilation and elevated 
intracranial pressure (ICP). Oral antihypertensive agents need to be started as soon as possible to control resistant HTN and facilitate the transition of care from ICU to long-term management. Arterial line placement is recommended to optimise blood pressure monitoring and medication titration. The guidelines for resistant HTN recommend angiotensin converting enzyme inhibitors (ACE-I) or angiotensin receptor blockers (ARB), calcium channel blocker (CCB) and a thiazide-like diuretic at maximal tolerated doses as an optimal triplets formula. $^{32}$ The CCB and ACE-I or ARB are widely accepted as the first-line and second-line drugs for resistant patients, but the choice of the third-line and fourthline antihypertensive agents varies greatly in real-world practice. Thiazide may cause hyponatraemia and worsen cerebral oedema in patients with large haemorrhage or mass effect. It should be used with caution. In a recent randomised trial, spironolactone was shown to be very effective for patients with resistant HTN. ${ }^{33}$ Spironolactone and $\alpha-/ \beta$-antagonists can be used as the third and fourth agents to maintain BP control while weaning off intravenous agents. During acute phase, patients may have resistant HTN due to sympathetic surge. A few weeks later, they may require fewer medications and be at risk of hypotension unless the doses of medications are adjusted promptly. ${ }^{16}$

\section{REVERSAL OF COAGULOPATHIES}

Coagulopathy, whether medication-induced or due to a systemic disease process, is associated with haematoma expansion, and increased risk of poor outcome and death. ${ }^{34}$ Approximately $12-20 \%$ of patients presenting with ICH are taking oral anticoagulants. Though acute reversal of coagulopathy has not been clearly shown to be beneficial in large randomised trials, rapid correction of coagulopathy should be considered in any potentially salvageable patient.

In December 2015, the Neurocritical Care Society together with the Society of Critical Care Medicine published guidelines for the reversal of antithrombotic agents in patients with ICH. ${ }^{35}$ Whenever ICH is diagnosed, any antithrombotic agent should be immediately discontinued. The method of reversal will depend on the agent used.

For all patients taking vitamin $\mathrm{K}$ antagonists (eg, warfarin), vitamin $\mathrm{K} 10 \mathrm{mg}$ and 3-factor or 4-factor prothrombin complex concentrates (PCCs) should be administered intravenously for patients with INR $\geq 1.4$. PCC is an inactivated concentrate of factors II, IX and $\mathrm{X}$, with variable amounts of factor VII. Variation in factor VII concentrations in PCC has led to their classification as either 3- or 4-factor. Unlike serum-containing products such as fresh frozen plasma (FFP), PCCs are lyophilised and can be reconstituted quickly for timely administration. In addition, the concentration of vitamin K-dependent clotting factors is $\sim 25$ times higher than plasma and can reverse coagulopathy quickly. The two 3-factor products currently available in the USA are Profilnine SD (Grifols Biologicals, Los Angeles, California, USA) and Bebulin VH (Baxter Healthcare Corporation, Westlake Village, California, USA). Kcentra (Beriplex outside the USA) is the first 4-factor PCG indicated for warfarin reversal in adults during acute major bleeding or a need for urgent surgery.

PCC is preferred over FFP due to more rapid correction of INR, lower volume and risk of infection, pulmonary oedema, Transfusion-Related Acute Lung Injury (TRALI) and Transfusion Associated Cardiac Overload (TACO). If repeat INR 15-60 min after PCC administration shows continued INR elevation above 1.4, consider further correction with 2-4 units FFP. Recombinant Factor VIIa (rFVIIa) has been associated with relatively high thrombosis rates and should only be considered in patients who will not accept blood products (eg, Jehovah's witness).

Direct thrombin inhibitors (DTIs; eg, dabigatran, argatroban and bivalirudin) have significantly less risk of $\mathrm{ICH}$ than vitamin $\mathrm{K}$ antagonists. However, haemorrhages do occur and reversal of coagulopathy is indicated if patient presents within 3-5 half-lives of drug exposure (or beyond in patient with renal insufficiency). Idarucizumab ( $5 \mathrm{~g}$ intravenous divided into two doses), a specific neutralising monoclonal antibody fragment for dabigatran, is recommended in cases of haemorrhage associated with dabigatran. ${ }^{36}$ If idarucizumab is not available, or if the haemorrhage is associated with a DTI other than dabigatran, 4-factor PCC ( 50 units $/ \mathrm{kg}$ ) or activated PCC (50 units/ $\mathrm{kg}$ ) is recommended. Haemodialysis can also be considered in patients with dabigatran-associated ICH and renal insufficiency, especially if continued haemorrhage despite first-line therapies.

For patients taking Factor Xa inhibitors (eg, rivaroxaban, apixaban and edoxaban), 4-factor PCC (50 units/ $\mathrm{kg}$ ) or activated PCC (50 units $/ \mathrm{kg}$ ) is recommended if the haemorrhage occurred within 3-5 half-lives of drug exposure (or in context of liver failure). If presenting within 2 hours of drug exposure, activated charcoal can be administrated to prevent further drug absorption. Laboratory testing is unlikely to be helpful in guiding treatment for these patients; therefore, reversal should be guided by bleeding (major or intracranial) instead. Andexanet alfa is a recombinant modified factor Xa that can bind and reverse oral and parenteral factor Xa inhibitors, including rivaroxaban, apixaban and edoxaban, and low-molecular-weight heparin. ${ }^{37}$ It has not been approved by the FDA for clinical use.

The guidelines for reversing warfarin and novel oral anticoagulants (NOAC) coagulopathies in patients with symptomatic ICH are shown in figure 3.

Reversal of unfractionated heparin is recommended for patients who develop ICH while on heparin infusion. Reversal of prophylactic subcutaneous heparin should only be considered if activated partial thormboplastin time (aPTT) is significantly prolonged in setting of new 


\section{Reversal of Coagulopathies}

\begin{tabular}{|c|c|c|}
\hline Warfarin & $\begin{array}{l}\text { Direct Thrombin Inhibitors } \\
\text { - Dabigatran }\end{array}$ & $\begin{array}{l}\text { Xa inhibitors } \\
\text { - Rivaroxaban, Apixaban, or Edoxaban }\end{array}$ \\
\hline 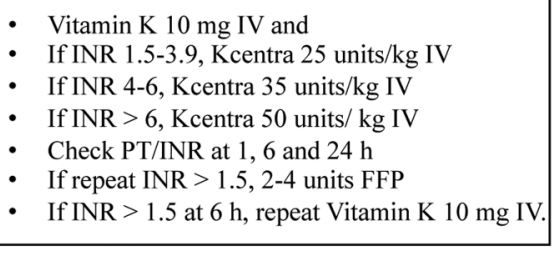 & $\begin{array}{l}\text { - If ingestion within } 2 \mathrm{~h} \text {, give one } \\
\text { dose activated charcoal orally. } \\
\text { - Idarucizumab (Praxbind): } 2.5 \mathrm{gm} \\
\text { IV q10 mins } x \text { 2. } \\
\text { - Idarucizumab will likely correct } \\
\text { aPTT and thrombin time } \\
\text { - Consider emergent dialysis in } \\
\text { patient with renal failure }\end{array}$ & $\begin{array}{l}\text { - If ingestion within } 2 \mathrm{~h} \text {, give one dose activated } \\
\text { charcoal orally. } \\
\text { - If reversal with PCC will be attempted, infuse } \\
\text { Kcentra } 50 \text { units/kg. } \\
\text { - Half life } 9-12 \mathrm{~h} \text {, Rivaroxaban and Apixaban are } \\
\text { not removed by dialysis. }\end{array}$ \\
\hline
\end{tabular}

Figure 3 The guidelines for reversing warfarin and NOAC coagulopathies in patients with symptomatic $\mathrm{ICH}$. ICH, intracerebral haemorrhage.

haemorrhage. Intravenous protamine (1 $\mathrm{mg}$ per every 100 units of heparin given in past 2-3 hours, maximum $50 \mathrm{mg}$ ) should be utilised and repeated at half of the initial dose if repeat aPTT remains elevated.

Reversal of low-molecular-weight heparin (low molecular weight heparin (LMWH); eg, enoxaparin, dalteparin, nadroparin and tinzaparin) is also recommended only if receiving therapeutic doses, rather than prophylactic doses. For enoxaparin administered within past 8 hours, $1 \mathrm{mg}$ of protamine per every $1 \mathrm{mg}$ of enoxaparin should be administered. If enoxaparin given 8-12 hours, $0.5 \mathrm{mg}$ of protamine per every $1 \mathrm{mg}$ of enoxaparin should be administered. For the reversal of dalteparin, nadroparin and tinzaparin, dose $1 \mathrm{mg}$ per every 100 anti-Xa units of LMWH, up to maximum $50 \mathrm{mg}$. This can be repeated at half of the initial dose if continued bleeding or patient has renal insufficiency. rFVIIa is generally not recommended, but can be considered if protamine contraindicated.

Heparinoids (eg, danaparoid) are not available in the USA, but are used in other countries. In ex vivo studies, danaparoid was not reversed with protamine, PCC, aPCC or FFP; therefore, these agents are not recommended for reversal in patients with ICH. rFVIIa (90 $\mathrm{gg} / \mathrm{kg}$ intravenous once) has shown some efficacy and therefore is recommended instead.

For thrombolytic (eg, recombinant tissue plasminogen activator (rtPA)) reversal, 10 units of cryoprecipitate may be considered. If the level of fibrinogen is $<150 \mathrm{mg} / \mathrm{dL}$ post cryoprecipitate use, consider additional cryoprecipitate administration. If cryoprecipitate is contraindicated or unavailable, an antifibrinolytic agent (tranexamic acid $10-15 \mathrm{mg} / \mathrm{kg}$ intravenous or $\varepsilon$-aminocaproic acid 4-5 g intravenous) can be considered.

For patients taking antiplatelet agents (eg, aspirin, clopidogrel and abciximab), platelet transfusion is not recommended routinely, regardless of antiplatelet agent, platelet function testing, haemorrhage volume or neurological examination. In a multicentre, open-label randomised trial at 60 hospitals in the Netherlands, UK and France, 190 patients with ICH on antiplatelet therapy for at least 7 days prior to ICH were randomly assigned to platelet transfusion and standard care. Platelet transfusion seems inferior to standard care for patients taking antiplatelet therapy before ICH. ${ }^{38}$

Platelet transfusion should be considered for patients with aspirin- or adenosine diphosphate receptor (ADP) inhibitor-associated ICH who will undergo a neurosurgical procedure. Platelet function testing prior to platelet transfusion should be performed if possible and timely results available. If platelet function is within normal limits or patient has documented antiplatelet resistance, platelet transfusion should be avoided. Platelet transfusion is not recommended for non-steroidal anti-inflammatory drugs (NSAIDs) or glycoprotein (GP) IIb/IIA inhibitor-related ICH. Desmopressin (ddAVP) $(0.4 \mu \mathrm{g} /$ $\mathrm{kg}$ intravenous once) can be considered in ICH associated with cyclooxygenase (COX) inhibitors or ADP receptor inhibitors. ${ }^{35}$

\section{Management of intraventricular haemorrhage and hydrocephalus}

Intraventricular haemorrhage (IVH) occurs in up to $45 \%$ of patients with ICH. It is associated with lower GCS and an independent predictor of poor outcome. ${ }^{39}$ External ventricular drain (EVD) placement should be considered in any patient with GCS $\leq 8$, significant IVH, hydrocephalus or evidence of transtentorial herniation. ${ }^{20}$ Elevated ICP $(>20 \mathrm{~mm} \mathrm{Hg})$ should be treated with hyperosmolar therapy (HTS and/or mannitol), cerebrospinal fluid drainage or sedation, though none of these therapies has been shown to improve outcomes. $^{12}$ 
Apart from clotting the cerebral aqueduct leading to obstructive hydrocephalus, intraventricular blood and its breakdown products cause inflammation of the ependymal layer and subependymal brain tissue. In addition, the clot also causes inflammation and fibrosis of the arachnoid granulations, leading to delayed communicating hydrocephalus. Intraventricular fibrinolysis with rtPA was an emerging therapy for clearing $\mathrm{IVH}$ as soon as possible. It was shown to clear IVH without increasing perihaemorrhagic oedema. ${ }^{40}$ Recently, a large, phase III, multicentre, randomised, placebo controlled clinical trial evaluating the use of intraventricular tPA administration in patients with IVH has completed enrolment. The preliminary results of the Clot Lysis: Evaluating Accelerated Resolution of Intraventricular Hemorrhage III (CLEAR III) trial showed no outcome benefit. Subgroup analysis showed reduced mortality in patients with large IVH (2016 International Stroke Conference Press Release-18 February 2016).

\section{SURGICAL INTERVENTION}

The International Surgical Trial in Intracerebral Hemorrhage (ISTICH) and the subsequent STICH II demonstrated no benefit for early haematoma evacuation in patients with supratentorial ICH. ${ }^{41}{ }^{42}$ Subgroup analysis shows a small survival benefit in patients with superficial lobar haemorrhages without significant improvement in functional outcomes.

Utilisation of minimally invasive techniques for clot evacuation, however, may be promising. ${ }^{43}$ In a clinical trial performed in China a decade ago, 377 patients with basal ganglia ICH were randomised to treatment with minimally invasive craniopuncture and needle aspiration versus conservative treatment. ${ }^{44}$ The study showed a significant improvement in neurological function at 2 weeks and 3 months without mortality benefit. The Minimally-Invasive Surgery plus rtPA for Intracerebral Hemorrhage Evacuation (MISTIE) phase II trial evaluated the utilisation of stereotactic clot catheterisation and intermittent dosing of rtPA to facilitate clot breakdown and aspiration. ${ }^{45}$ It showed a trend towards improved outcomes in the surgical patients compared with the medically managed patients. The ongoing MISTIE III trial has added a Stereotactic CT-guided Endoscopic Surgery arm. Preliminary data showed that the newer trans-sylvian, transinsular minimal invasive approaches may yield better results due to relative sparing of cortical function. ${ }^{46}{ }^{47}$ Randomised controlled studies are required to evaluate their clinical benefit.

Unlike supratentorial ICH, cerebellar ICH is considered a neurosurgical emergency and evacuation is recommended per current guidelines given the high morbidity from rapid development of brainstem compression. ${ }^{20}$ Surgical indications include haematoma size $>3 \mathrm{~cm}$ in diameter, brainstem compression or hydrocephalus. EVD placement alone is not sufficient treatment and may lead to upward herniation and further neurological decline. ${ }^{12} 27$ Select patients with large lobar ICH or temporal lobe haemorrhage may also benefit from emergent haematoma evacuation.

\section{MANAGEMENT OF PERIHAEMIATOMA OEDEIMA}

Perihaematomal oedema (PHE) develops within the first few days after ICH and may cause elevated ICP, mass effect, midline shift and brain herniation. ${ }^{48} 4950$ The degree and growth of PHE are strongly related to the size of haematoma. ${ }^{48}$ Data from several clinical trials indicate that the absolute increase in PHE during the first 24-72 hours was associated with worse functional outcomes at 90 days after ICH. ${ }^{49} 50$

Patients with asymptomatic PHE require no specific treatment except maintaining a normal sodium goal. There is no indication for routine use of osmotic agents, such as mannitol or HTS, in most patients with small ICH.

However, mannitol and HTS are the first-line medical therapies for patients with symptomatic cerebral oedema and elevated ICP. Mannitol is an osmotic diuretic. It increases water excretion by the kidneys and reduces cerebral oedema and ICP. HTS increases plasma osmolarity and the flow of excess water from cerebral tissue to the blood via the osmotic gradient.

In a small retrospective study, treatment with $23.4 \%$ of HTS was associated with rapid reversal of transtentorial herniation and reduced ICP. ${ }^{51}$ Early continuous infusion of $3 \%$ of HTS for sodium goal of $145-155 \mathrm{mmol} / \mathrm{L}$ was associated with less cerebral oedema and ICP crisis $(>20 \mathrm{~mm} \mathrm{Hg}$ for $>20 \mathrm{~min}$ or new anisocoria) than historical control $(\mathrm{n}=64) .{ }^{52}$ A meta-analysis performed in 2011 showed that HTS is slightly more effective than mannitol for the treatment of elevated ICP. ${ }^{53} \mathrm{~A}$ recent analysis of the INTERACT2 data showed that mannitol seems safe, but might not improve outcome in patients with acute $\mathrm{ICH}^{54}$

In real-world practice, the patient's medical history and the side effect profiles of mannitol and HTS may be the major factors for choosing an osmotic agent for an individual patient. For example, patients with congestive heart failure should receive a bolus of mannitol or $23.4 \%$ of HTS, whereas continuous infusion of $3 \%$ of HTS can be used for patients with dehydration or decreased urine output.

Of note, Minimally Invasive Surgery Plus tPA for ICH Evacuation (MISTIE) II study revealed significant association of haematoma removal and oedema reduction in the surgical group. ${ }^{45}$ Additional study is warranted to show the effect on outcomes.

\section{SEIZURE PROPHYLAXIS AND TREATMENT}

Patient with ICH have up to $16 \%$ risk of clinical seizures within 1 week, with majority occurring at or near onset. $^{55}{ }^{56}$ Lobar ICH with cortical involvement is the most important risk factor. ${ }^{57}$ Prospective and populationbased studies have shown no association between clinical 
seizures and neurological outcome or mortality. ${ }^{58} 59$ Between $28 \%$ and $31 \%$ of patients will have electrographic seizures on continuous electroencephalographic monitoring. ${ }^{58}$ The clinical impact of subclinical seizures is unclear. Prophylactic phenytoin usage has been associated with worse outcomes in several studies. ${ }^{59} 60$

Continuous EEG monitoring should be considered for patients with ICH with depressed mental status out of proportion to the degree of brain injury. Clinical seizures should be treated with antiepileptic medications, as should electrographic seizures accompanied by changes in mental status. ${ }^{20}$

\section{GLUCOSE MANAGEMENT}

Hyperglycaemia on admission is associated with worse morbidity and mortality independent of the presence of diabetes. ${ }^{61}$ However, tight glucose control with target glucose $80-110 \mathrm{mg} / \mathrm{dL}$ increases hypoglycaemia and the risk of morbidity and mortality. ${ }^{62}$ Care should be taken to avoid hyperglycaemia and hypoglycaemia. ${ }^{20}$ It is reasonable to target glucose level at $100-150 \mathrm{mg} / \mathrm{dL}$ for patients with ICH.

\section{FEVER CONTROL}

Fever is common after ICH, particularly in patients with intraventricular extension. Sustained fever after ICH is an independent prognostic factor for worse outcome. ${ }^{63}$ However, neither therapeutic hypothermia nor normothermia was shown to improve outcome. ${ }^{64}{ }^{65}$ In a retrospective case-control study of patients with spontaneous ICH having two consecutive fevers $\geq 38.3^{\circ} \mathrm{C}$ despite acetaminophen administration, therapeutic normothermia was shown to be associated with increased duration of sedation, mechanical ventilation and Neuro-ICU length of stay without discharge outcome benefit. ${ }^{65}$ Normothermia or hypothermia should not be used after ICH except in the setting of clinical trials.

\section{DEEP VEIN THROMBOSIS PROPHYLAXIS AND TREATMENT}

There is a significant risk of venous thromboembolism (VTE) in patients with ICH, with the rate of symptomatic deep vein thrombosis (DVT) at $1-5 \%{ }^{66-70}$ The incidence of symptomatic pulmonary embolism (PE) is $\sim 0.5-2 \%{ }^{68-70} \mathrm{Up}$ to half of the PE are fatal. It is therefore essential to prevent VTE.

Guidelines published by the Neurocritical Care Society in December 2015 recommend the initiation of mechanical VTE prophylaxis, preferably with intermittent pneumatic compression (IPC) devices at the time of admission. ${ }^{20} 71$ If IPC devices are unavailable, graduated compression stockings (GCS) can be utilised. Prophylactic doses of subcutaneous unfractionated heparin or LMWH should be started in patients with stable haematomas within 48 hours of admission. Mechanical VTE prophylaxis should be continued after initiation of pharmacological prophylaxis.
Patients with DVT or PE should be considered for systemic anticoagulation depending on stability of the haematoma, cause of haemorrhage and time since presentation. If systemic anticoagulation is contraindicated, inferior vena cava filter placement should be considered. ${ }^{20} 71$

\section{PROGNOSIS}

ICH is the most debilitating and deadly type of stroke. A number of factors may affect outcome after ICH, including haematoma volume and location, haematoma expansion, age, GCS score on presentation, intraventricular extension and anticoagulant use. The ICH score was developed to predict 30-day mortality rate and functional outcomes at 1 year. ${ }^{72}{ }^{73}$ Most patients die from ICH within the initial hospitalisation due to presumed poor outcome leading to withdrawal of care. ${ }^{74}$ None of the existing prediction models, including the ICH score, is proven reliable. Several studies have shown that withdrawal of support and early care limitations, such as donot-resuscitate (DNR) orders, within the first day of hospitalisation are an independent predictor of poor outcome. $^{73-76}$ This raises concerns for 'self-fulfilling prophecies'. Of note, ICH mortality rate in China was much lower than that in the USA, ${ }^{77}$ likely due to fewer withdrawal of life support.

The current AHA/ASA guidelines recommend early and aggressive care after ICH and postponement of any new DNR orders until at least the second full day of treatment. Patients with pre-existing DNR orders are excluded from this recommendation. However, DNR status should not limit appropriate medical and surgical interventions, unless explicitly indicated..$^{20}$

\section{CONCLUSIONS}

ICH is a medical emergency with high risk of morbidity and mortality. Recent advances in early diagnosis and neurocritical care have contributed to improved survival. Continued research into prevention and effective therapy is pivotal in reducing disease burden and improving functional recovery.

Contributors CKD is involved in drafting the work. WY is responsible revising the manuscript critically for important intellectual content.

Competing interests None declared.

Provenance and peer review Commissioned; internally peer reviewed.

Data sharing statement No additional data are available.

Open Access This is an Open Access article distributed in accordance with the Creative Commons Attribution Non Commercial (CC BY-NC 4.0) license, which permits others to distribute, remix, adapt, build upon this work noncommercially, and license their derivative works on different terms, provided the original work is properly cited and the use is non-commercial. See: http:// creativecommons.org/licenses/by-nc/4.0/

\section{REFERENCES}

1. Qureshi Al, Tuhrim S, Broderick JP, et al. Spontaneous intracerebral hemorrhage. N Engl J Med 2001;344:1450-60.

2. Flaherty ML, Haverbusch $M$, Sekar $P$, et al. Long-term mortality after intracerebral hemorrhage. Neurology 2006;66:1182-6. 
3. Ariesen MJ, Claus SP, Rinkel GJ, et al. Risk factors for intracerebral hemorrhage in the general population: a systematic review. Stroke 2003;34:2060-5.

4. Meretoja A, Strbian D, Putaala J, et al. SMASH-U: a proposal for etiologic classification of intracerebral hemorrhage. Stroke 2012;43:2592-7.

5. van Asch CJ, Luitse MJ, Rinkel GJ, et al. Incidence, case fatality, and functional outcome of intracerebral haemorrhage over time, according to age, sex, and ethnic origin: a systematic review and meta-analysis. Lancet Neurol 2010;9:167-76.

6. Feigin VL, Lawes CM, Bennett DA, et al. Worldwide stroke incidence and early case fatality reported in 56 population-based studies: a systematic review. Lancet Neurol 2009;8:355-69.

7. Mozaffarian D, Benjamin EJ, Go AS, et al. Heart disease and stroke statistics-2016 update a report from the American Heart Association. Circulation 2015;131:e29-322.

8. Zahuranec DB, Gonzales NR, Brown DL, et al. Presentation of intracerebral haemorrhage in a community. J Neurol Neurosurg Psychiatr 2006;77:340-4

9. Diringer MN, Edwards DF. Admission to a neurologic/neurosurgical intensive care unit is associated with reduced mortality rate after intracerebral hemorrhage. Crit Care Med 2001;29:635-40.

10. Mirski MA, Chang CW, Cowan R. Impact of a neuroscience intensive care unit on neurosurgical patient outcomes and cost of care: evidence-based support for an intensivist-directed specialty ICU model of care. J Neurosurg Anesthesiol 2001;13:83-92.

11. Suarez JI, Zaidat OO, Suri MF, et al. Length of stay and mortality in neurocritically ill patients: impact of a specialized neurocritical care team. Crit Care Med 2004;32:2311-7.

12. Chan S, Hemphill JC. Critical care management of intracerebral hemorrhage. Crit Care Clin 2014;30:699-717.

13. Cai $X$, Rosand $J$. The evaluation and management of adult intracerebral hemorrhage. Semin Neurol 2015;35:638-45.

14. Greenberg SM. Amyloid angiopathy. Neurology 1997:48:291.

15. Martini SR, Flaherty ML, Brown WM, et al. Risk factors for intracerebral hemorrhage differ according to hemorrhage location. Neurology 2012;79:2275-82.

16. Smith EE, Rosand J, Greenberg SM. Hemorrhagic stroke. Neuroimaging Clin N Am 2005;15:259-72, ix.

17. Divani AA, Majidi S, Luo X, et al. The ABCs of accurate volumetric measurement of cerebral hematoma. Stroke 2011;42:1569-74.

18. Kothari RU, Brott T, Broderick JP, et al. The ABCs of measuring intracerebral hemorrhage volumes. Stroke 1996;27:1304-5.

19. Webb AJS, Ullman NL, Morgan TC, et al. Accuracy of the ABC/2 score for intracerebral hemorrhage: systematic review and analysis of MISTIE, CLEAR-IVH, and CLEAR III. Stroke 2015;46: 2470-6.

20. Becker KJ, Baxter AB, Bybee HM, et al. Extravasation of radiographic contrast is an independent predictor of death in primary intracerebral hemorrhage. Stroke 1999;30:2025-32.

21. Orito $\mathrm{K}$, Hirohata $\mathrm{M}$, Nakamura $\mathrm{Y}$, et al. Leakage sign for primary intracerebral hemorrhage: a novel predictor of hematoma growth. Stroke 2016:47:958-63.

22. Moon JS, Janjua N, Ahmed S, et al. Prehospital neurologic deterioration in patients with intracerebral hemorrhage. Crit Care Med 2008;36:172-5.

23. Fan JS, Huang HH, Chen YC, et al. Emergency department neurologic deterioration in patients with spontaneous intracerebral hemorrhage: incidence, predictors, and prognostic significance. Acad Emerg Med 2012;19:133-8.

24. Brott T, Broderick J, Kothari R, et al. Early hemorrhage growth in patients with intracerebral hemorrhage. Stroke 1997;28:1-5.

25. Rodriguez-Luna D, Piñeiro S, Rubiera M, et al. Impact of blood pressure changes and course on hematoma growth in acute intracerebral hemorrhage. Eur J Neurol 2013;20:1277-83.

26. Hemphill JC III, Greenberg SM, Anderson CS, et al. Guidelines for the management of spontaneous intracerebral hemorrhage. A guideline for healthcare professionals from the American Heart Association/American Stroke Association. Stroke 2015;46:2032-60.

27. Sakamoto $Y$, Koga $M$, Yamagami $H$, et al. Systolic blood pressure after intravenous antihypertensive treatment and clinical outcomes in hyperacute intracerebral hemorrhage: the stroke acute management with urgent risk-factor assessment and improvement-intracerebral hemorrhage study. Stroke 2013;44:1846-51.

28. Zazulia AR, Diringer MN, Videen TO, et al. Hypoperfusion without ischemia surrounding acute intracerebral hemorrhage. J Cereb Blood Flow Metab 2001:21:804-10.

29. Butcher KS, Jeerakathil T, Hill M, et al. The intracerebral hemorrhage acutely decreasing arterial pressure trial. Stroke 2013;44:620-6.
30. Anderson CS, Heeley E, Huang $Y$, et al. Rapid blood-pressure lowering in patients with acute intracerebral hemorrhage. $N$ Engl J Med 2013;368:2355-65.

31. Qureshi Al, Palesch YY, Barsan WG, et al. Intensive blood-pressure lowering in patients with acute cerebral hemorrhage. N Engl J Med 2016;375:1033-43.

32. Calhoun DA, Jones D, Textor $\mathrm{S}$, et al. Resistant hypertension: diagnosis, evaluation, and treatment. A scientific statement from the American Heart Association Professional Education Committee of the Council for High Blood Pressure Research. Hypertension 2008:51:1403-19.

33. Williams B, MacDonald TM, Morant S, et al. Spironolactone versus placebo, bisoprolol, and doxazosin to determine the optimal treatment for drug-resistant hypertension (PATHWAY-2): a randomised, double-blind, crossover trial. Lancet 2015;386:2059-68.

34. Huhtakangas J, Tetri S, Juvela S, et al. Effect of increased warfarin use on warfarin-related cerebral hemorrhage: a longitudinal population-based study. Stroke 2011;42:2431-5.

35. Frontera JA, Lewin JJ, Rabinstein AA. Guideline for reversal of antithrombotics in intracranial hemorrhage. Neurocrit Care 2015;24:6-46.

36. Pollack CV Jr, Reilly PA, Eikelboom J, et al. Idarucizumab for dabigatran reversal. N Engl J Med 2015;373:511-20.

37. Siegal DM, Curnutte JT, Connolly SJ, et al. Andexanet Alfa for the reversal of factor Xa inhibitor activity. N Engl J Med 2015;373:2413.

38. Baharoglu Ml, Cordonnier C, Al-Shahi Salman R, et al. Platelet transfusion versus standard care after acute stroke due to spontaneous cerebral haemorrhage associated with antiplatelet therapy (PATCH): a randomised, open-label, phase 3 trial. Lancet 2016;387:2605-13.

39. Hallevi $\mathrm{H}$, Albright KC, Aronowski J, et al. Intraventricular hemorrhage: anatomic relationships and clinical implications. Neurology 2008;70:848-52.

40. Volbers B, Wagner I, Willfarth W, et al. Intraventricular fibrinolysis does not increase perihemorrhagic edema after intracerebral hemorrhage. Stroke 2013;44:362-6.

41. Mendelow AD, Gregson BA, Fernandes HM, et al. Early surgery versus initial conservative treatment in patients with spontaneous supratentorial intracerebral haematomas in the International Surgical Trial in Intracerebral Haemorrhage (STICH): a randomised trial. Lancet 2005;365:387-97.

42. Mendelow AD, Gregson BA, Rowan EN, et al. Early surgery versus initial conservative treatment in patients with spontaneous supratentorial lobar intracerebral haematomas (STICH II): a randomised trial. Lancet 2013:382:397-408.

43. Dey M, Stadnik A, Awad IA. Spontaneous intracerebral and intraventricular hemorrhage: advances in minimally invasive surgery and thrombolytic evacuation, and lessons learned in recent trials. Neurosurgery 2014;74(Suppl 1):S142-50.

44. Wang WZ, Jiang B, Liu HM, et al. Minimally invasive craniopuncture therapy vs. conservative treatment for spontaneous intracerebral hemorrhage: results from a randomized clinical trial in China. Int J Stroke 2009;4:11-16.

45. Mould WA, Carhuapoma JR, Muschelli J, et al. Minimally invasive surgery plus recombinant tissue-type plasminogen activator for intracerebral hemorrhage evacuation decreases perihematoma edema. Stroke 2013;44:627-34.

46. Spiotta AM, Fiorella D, Vargas J, et al. Initial multicenter technical experience with the Apollo device for minimally invasive intracerebral hematoma evacuation. Neurosurgery 2015;11(Suppl 2):243-51; discussion 251

47. Przybylowski CJ, Ding D, Starke RM, et al. Endoport-assisted surgery for the management of spontaneous intracerebral hemorrhage. J Clin Neurosci 2015;22:1727-32.

48. Arima $\mathrm{H}$, Wang JG, Huang $\mathrm{Y}$, et al. Significance of perihematomal edema in acute intracerebral hemorrhage: the INTERACT trial. Neurology 2009;73:1963-8.

49. Murthy SB, Moradiya Y, Dawson J, et al. Perihematomal edema and functional outcomes in intracerebral hemorrhage: influence of hematoma volume and location. Stroke 2015;46:3088-92.

50. Yang J, Arima H, Wu G, et al. Prognostic significance of perihematomal edema in acute intracerebral hemorrhage: pooled analysis from the intensive blood pressure reduction in acute cerebral hemorrhage trial studies. Stroke 2015;46:1009-13.

51. Koenig MA, Bryan M, Lewin JL III, et al. Reversal of transtentoria herniation with hypertonic saline. Neurology 2008;70:1023-9.

52. Wagner I, Hauer EM, Staykov D, et al. Effects of continuous hypertonic saline infusion on perihemorrhagic edema evolution. Stroke 2011;42:1540-5.

53. Kamel H, Navi BB, Nakagawa K, et al. Hypertonic saline versus mannitol for the treatment of elevated intracranial pressure: a 
meta-analysis of randomized clinical trials. Crit Care Med 2011;39:554-9.

54. Wang X, Arima H, Yang J, et al. Mannitol and outcome in intracerebral hemorrhage: propensity score and multivariable Intensive Blood Pressure Reduction in Acute Cerebral Hemorrhage Trial 2 results. Stroke 2015;46:2762-7.

55. De Herdt V, Dumont $\mathrm{F}$, Hénon $\mathrm{H}$, et al. Early seizures in intracerebral hemorrhage: incidence, associated factors, and outcome. Neurology 2011;77:1794-800.

56. Bladin CF, Alexandrov AV, Bellavance A, et al. Seizures after stroke: a prospective multicenter study. Arch Neurol 2000;57:1617-22.

57. Passero S, Rocchi R, Rossi S, et al. Seizures after spontaneous supratentorial intracerebral hemorrhage. Epilepsia 2002;43:1175-80.

58. Mullen MT, Kasner SE, Messé SR. Seizures do not increase in-hospital mortality after intracerebral hemorrhage in the nationwide inpatient sample. Neurocrit Care 2013;19:19-24.

59. Naidech AM, Garg RK, Liebling S, et al. Anticonvulsant use and outcomes after intracerebral hemorrhage. Stroke 2009;40:3810-15.

60. Messé SR, Sansing LH, Cucchiara BL, et al. Prophylactic antiepileptic drug use is associated with poor outcome following ICH. Neurocrit Care 2009;11:38-44.

61. Passero S, Ciacci G, Ulivelli M. The influence of diabetes and hyperglycemia on clinical course after intracerebral hemorrhage. Neurology 2003;61:1351-6.

62. Finfer S, Chittock DR, Su SY, et al. Intensive versus conventional glucose control in critically ill patients. N Engl J Med 2009;360:1283-97.

63. Schwarz S, Häfner K, Aschoff A, et al. Incidence and prognostic significance of fever following intracerebral hemorrhage. Neurology 2000;54:354-61.

64. Kollmar R, Staykov D, Dörfler A, et al. Hypothermia reduces perihemorrhagic edema after intracerebral hemorrhage. Stroke 2010;41:1684-9.

65. Lord AS, Karinja S, Lantigua $\mathrm{H}$, et al. Therapeutic temperature modulation for fever after intracerebral hemorrhage. Neurocrit Care 2014;21:200-6.

66. Lacut K, Bressollette L, Le Gal G, et al. Prevention of venousthrombosis in patients with acute intracerebral hemorrhage. Neurology 2005;65:865-9.
67. Goldstein JN, Fazen LE, Wendell L, et al. Risk of thromboembolism following acute intracerebral hemorrhage. Neurocrit Care 2009;10:28-34.

68. Gregory PC, Kuhlemeier KV. Prevalence of venous thromboembolism in acute hemorrhagic and thromboembolic stroke. Am J Phys Med Rehabil 2003;82:364-9.

69. Kim KS, Brophy GM. Symptomatic venous thromboembolism: incidence and risk factors in patients with spontaneous or traumatic intracranial hemorrhage. Neurocrit Care 2009;11: 28-33.

70. Diringer MN, Skolnick BE, Mayer SA, et al. Thromboembolic events with recombinant activated factor VII in spontaneous intracerebral hemorrhage: results from the factor seven for acute hemorrhagic stroke (FAST) trial. Stroke 2010;41:48-53.

71. Nyquist $P$, Bautista $C$, Jichici $D$, et al. Prophylaxis of venous thrombosis in neurocritical care patients: an evidence-based guideline-a statement for healthcare professionals from the Neurocritical Care Society. Neurocrit Care 2016;24: 47-60.

72. Hemphill JC, Bonovich DC, Besmertis L, et al. The ICH score: a simple, reliable grading scale for intracerebral hemorrhage. Stroke 2001;32:891-7.

73. Hemphill JC, Farrant M, Neill TA. Prospective validation of the ICH Score for 12-month functional outcome. Neurology 2009;73:1088-94.

74. Hemphill JC, Newman J, Zhao S, et al. Hospital usage of early do-not-resuscitate orders and outcome after intracerebral hemorrhage. Stroke 2004;35:1130-4.

75. Zahuranec DB, Brown DL, Lisabeth LD, et al. Early care limitations independently predict mortality after intracerebral hemorrhage. Neurology 2007;68:1651-7.

76. Zahuranec DB, Morgenstern LB, Sánchez BN, et al. Do-not-resuscitate orders and predictive models after intracerebral hemorrhage. Neurology 2010;75:626-33.

77. Wang W, Lu J, Wang C, et al. Prognostic value of ICH score and $\mathrm{ICH}-\mathrm{GS}$ score in Chinese intracerebral hemorrhage patients: analysis from the China National Stroke Registry (CNSR). PLoS ONE 2013;8:e77421. 